\title{
Apoptosis resistance in epithelial tumors is mediated by tumor-cell-derived interleukin-4
}

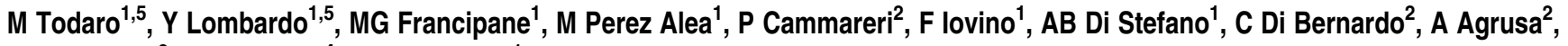 \\ G Condorelli ${ }^{3}, \mathrm{H}$ Walczak ${ }^{*, 4}$ and $\mathrm{G} \mathrm{Stassi^{*,1 }}$
}

\begin{abstract}
We investigated the mechanisms involved in the resistance to cell death observed in epithelial cancers. Here, we identify that primary epithelial cancer cells from colon, breast and lung carcinomas express high levels of the antiapoptotic proteins PED, cFLIP, Bcl-xL and Bcl-2. These cancer cells produced interleukin-4 (IL-4), which amplified the expression levels of these antiapoptotic proteins and prevented cell death induced upon exposure to TRAIL or other drug agents. IL-4 blockade resulted in a significant decrease in the growth rate of epithelial cancer cells and sensitized them, both in vitro and in vivo, to apoptosis induction by TRAIL and chemotherapy via downregulation of the antiapoptotic factors PED, cFLIP, Bcl-xL and Bcl-2. Furthermore, we provide evidence that exogenous IL-4 was able to upregulate the expression levels of these antiapoptotic proteins and potently stabilized the growth of normal epithelial cells rendering them apoptosis resistant. In conclusion, IL-4 acts as an autocrine survival factor in epithelial cells. Our results indicate that inhibition of IL-4/L-4R signaling may serve as a novel treatment for epithelial cancers.
\end{abstract}

Cell Death and Differentiation (2008) 15, 762-772; doi:10.1038/sj.cdd.4402305; published online 18 January 2008

Resistance to induction of cell death in cancer cells represents one of the major obstacles to successful cancer treatment. Multiple mechanisms of drug resistance in tumor cells have been identified, including decreased cellular uptake or increased cellular efflux of chemotherapeutic drugs as well as alterations in signaling pathways controlling the cell cycle or induction of cell death by apoptosis. ${ }^{1}$ Combination of different conventional therapies, including chemotherapy, radiation and surgery, so far have had only a limited success regarding disease-free and/or overall survival.

One of the hallmarks of cancer cells implicated in tumor development as well as metastasis formation is the resistance to apoptosis induction by both death ligands and chemotherapeutic drugs, which trigger the 'extrinsic' and the 'intrinsic' apoptotic pathways, respectively. ${ }^{1-3}$ The death ligand TRAIL (Apo2L) has been shown to specifically induce apoptosis in many tumor cell lines while sparing most normal cells. ${ }^{4}$ Similar to CD95 (Fas/APO-1), binding of TRAIL receptor 1 (TRAIL-R1/DR4) and TRAIL-R2 (Apo2, DR5, KILLER and TRICK2) by its ligand induces receptor clustering and formation of the death-inducing signaling complex (DISC). ${ }^{5}$ Activation of caspases 8 and 10 at the TRAIL DISC can be inhibited by recruitment of the caspase 8/10-homologous proteins cFLIP or PED/PEA-15. ${ }^{6-8}$ By contrast, antineoplastic drugs are a class of cytotoxic compounds that primarily activate the intrinsic apoptosis pathway, mostly via induction or activation of the $\mathrm{BH} 3$-only members of the Bcl-2 family, which results in the release of death factors, such as cytochrome $c$ and Smac/DIABLO (second mitochondria-derived activator of caspases/direct IAP-binding protein with low pl) from mitochondria. ${ }^{9}$ Both pathways converge in the activation of a caspase cascade. Interestingly, epithelial cancer cells, which are resistant to death receptorinduced apoptosis, are often found to be co-resistant to apoptosis induction by chemotherapeutic drugs and radiation. ${ }^{10,11}$

Several cytokines have been found to be secreted in the tumor microenvironment by cancer or infiltrating T cells. ${ }^{12} \mathrm{We}$ had previously found that in Graves' disease, infiltrating T helper type $2\left(\mathrm{~T}_{\mathrm{H}} 2\right)$ cells produce interleukin-4 (IL-4) and interleukin-10 (IL-10), which make thyrocytes refractory to the apoptosis-inducing effects of the CD95 ligand (CD95L/ FasL). ${ }^{13}$ We next examined the thyroid cancer microenvironment for a possible presence of these two cytokines and surprisingly found that the tumor cells themselves, rather than infiltrating T cells, produced both IL-4 and IL-10. IL-4 and IL-10 are pleiotropic cytokines with important physiological functions in the regulation of the immune response. IL-4 plays a central role in regulating the differentiation of antigenstimulated naive $\mathrm{T}$ cells as it determines these cells to develop into IL-4-producing $\mathrm{T}_{\mathrm{H}} 2$ cells, which can then also produce IL-5, IL-10 and IL-13. ${ }^{14}$ In addition, $\mathrm{T}_{\mathrm{H}} 2$ cytokines

${ }^{1}$ Department of Surgical and Oncological Sciences, University of Palermo, Palermo, Italy; ${ }^{2}$ Department of Genurto, University of Palermo, Palermo, Italy; ${ }^{3}$ Department of Cellular and Molecular Biology and Pathology, University of Naples 'Federico II', Naples, Italy and ${ }^{4}$ Division of Apoptosis Regulation, German Cancer Research Center (DKFZ), Heidelberg, Germany

${ }^{*}$ Corresponding authors: G Stassi, Cellular and Molecular Pathophysiology Laboratory, Department of Surgical and Oncological Sciences, University of Palermo, Via Liborio Giuffrè, 5, Palermo 90127, Italy. Tel: + 091655 3211; Fax: + 091655 3238; E-mail: gstassi@tiscali.it or

H Walczak, Division of Apoptosis Regulation, German Cancer Research Center (DKFZ), Im Neuenheimer Feld, Heidelberg, Germany. Tel: + 496221423700 ;

Fax: + 496221 423699; E-mail: h.walczak@dkfz.de

${ }^{5}$ These authors contributed equally to this work.

Keywords: apoptosis; cancer; chemotherapy; cytokines

Abbreviations: IL-4, interleukin-4; IL-10, interleukin-10; $T_{H} 2$, T helper type 2; Abs, antibodies; anti-IL-4, interleukin-4-neutralizing monoclonal antibody

Received 20.6.07; revised 21.11.07; accepted 27.11.07; Edited by SJ Martin; published online 18.1.08 
downregulate antitumor immunity leading to cancer progression and metastasis formation. ${ }^{15}$

We found that IL-4 and IL-10 induced growth and resistance to chemotherapy and death ligand-induced apoptosis in thyroid carcinomas. Interestingly, only the concomitant inhibition of IL-4 and IL-10 resulted in sensitization to apoptosis by chemotherapy and death ligands. ${ }^{16,17}$ Here, we studied whether the production of IL-4 and/or IL-10 and the consequent modulation of apoptosis-related proteins, conferring refractoriness to death ligand- and drug-induced apoptosis, may be a mechanism involved in cell survival, tumor progression and therapy resistance in other epithelial cancer cells.

\section{Results}

Epithelial cancer cells are resistant to apoptosis induction. To determine the apoptosis sensitivity of primary human epithelial cancer cells to chemotherapy and TRAIL, we isolated primary cancer cells from 20 colon, 10 breast and 4 lung, and cultivated them in the presence or absence of either chemotherapeutics usually used to treat these tumor types or with a recombinant isoleucine-zippertagged form of human TRAIL (iz-TRAIL). The applied concentration of each chemotherapeutic drug and of TRAIL was determined by time-course and dose-response studies (Figure 1a). In line with the modest efficacy reported in clinical trials, we found that primary epithelial cancer cells of all the examined histotypes only exhibited moderate sensitivity to both chemotherapy and TRAIL even at times and doses higher than those used in the clinical setting (Figure 1a).

With respect to TRAIL, this result is in contrast to the expectations from studies with cancer cell lines but it is indeed in line with the rather modest efficacy reported from recent clinical trials with various TRAIL receptor agonists. This resistance was even maintained when TRAIL or the chemotherapeutic agents were used at very high concentrations or for extended times (Figure 1a). Of note, the degree of resistance to cell death induction by apoptosis in the different tumor histotypes was quite uniform within the cohorts studied (Figure 1b and c).

Epithelial cancer cells express high levels of antiapoptotic proteins. To determine the mechanisms responsible for TRAIL refractoriness, we first investigated the presence of the two death-inducing TRAIL receptors, TRAIL-R1 and TRAIL-R2, showing that both were abundantly expressed on the surface of colon, breast and lung cancer cells (Figure 2a). We thus examined whether aberrant expression of pro- and antiapoptotic factors could be implicated in the observed impairment of the extrinsic and/ or intrinsic apoptosis signaling pathway.

We therefore compared the expression of key intracellular regulators of apoptosis in normal versus cancer cells from colon, breast and lung, and we found that PED/PEA-15 and
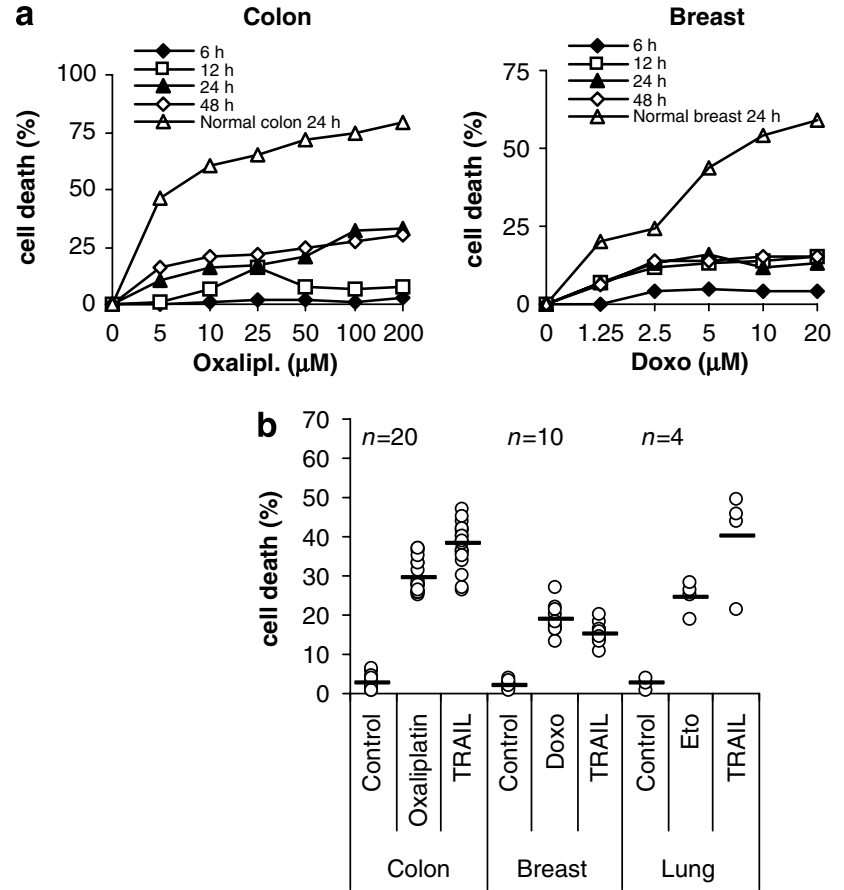
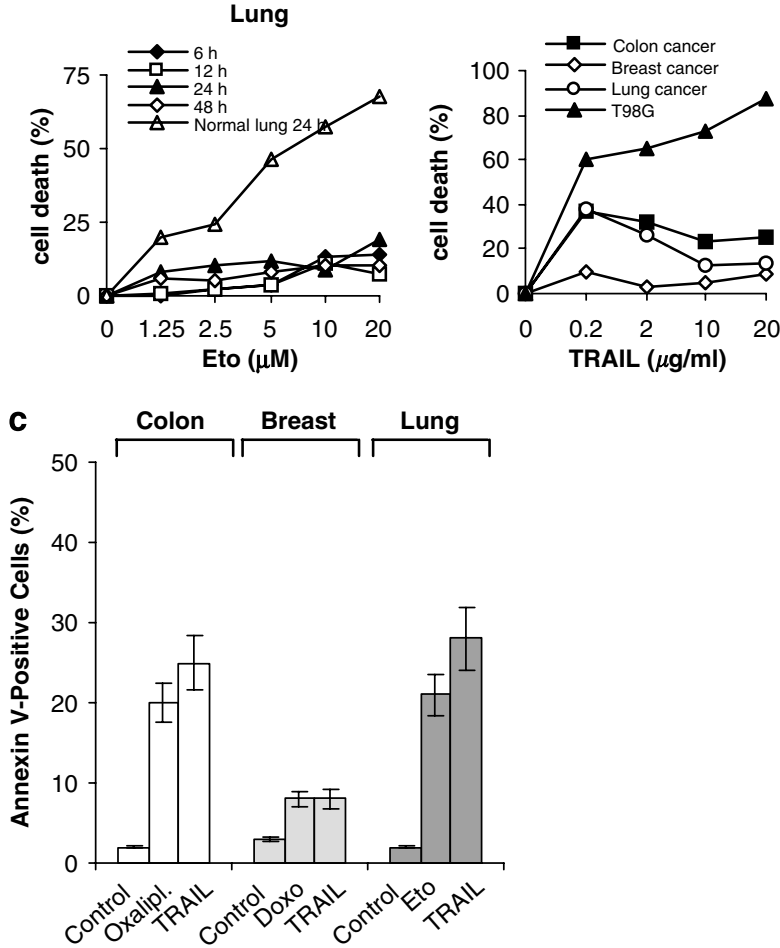

Figure 1 Cell death induction by chemotherapy and TRAIL in epithelial cancer cells. (a) Dose-response curves of epithelial cancer cells for oxaliplatin (oxalipl; 0-200 $\mu \mathrm{M}$ ), doxorubicin (doxo; $0-20 \mu \mathrm{M}$ ) and etoposide (eto; $0-20 \mu \mathrm{M})$ up to $48 \mathrm{~h}$ treatment and for TRAIL $(0-20 \mu \mathrm{g} / \mathrm{ml})$ after $12 \mathrm{~h}$ treatment. (b) Cell death of colon, breast and lung cancer cells in the presence or absence of oxaliplatin $(100 \mu \mathrm{M})$, doxorubicin (doxo; $5 \mu \mathrm{M}$ ), etoposide (eto; $5 \mu \mathrm{M})$ for $24 \mathrm{~h}$ or TRAlL ( $200 \mathrm{ng} / \mathrm{ml}$ ) for $12 \mathrm{~h}$. Each point represents data from an individual patient. Data are mean \pm S.D. of 20 independent experiments for colon, 10 for breast and 4 for lung. (c) Percentage of annexin V-positive cells assessed by cytometry on colon, breast and lung epithelial cancer cells treated as in (b) 

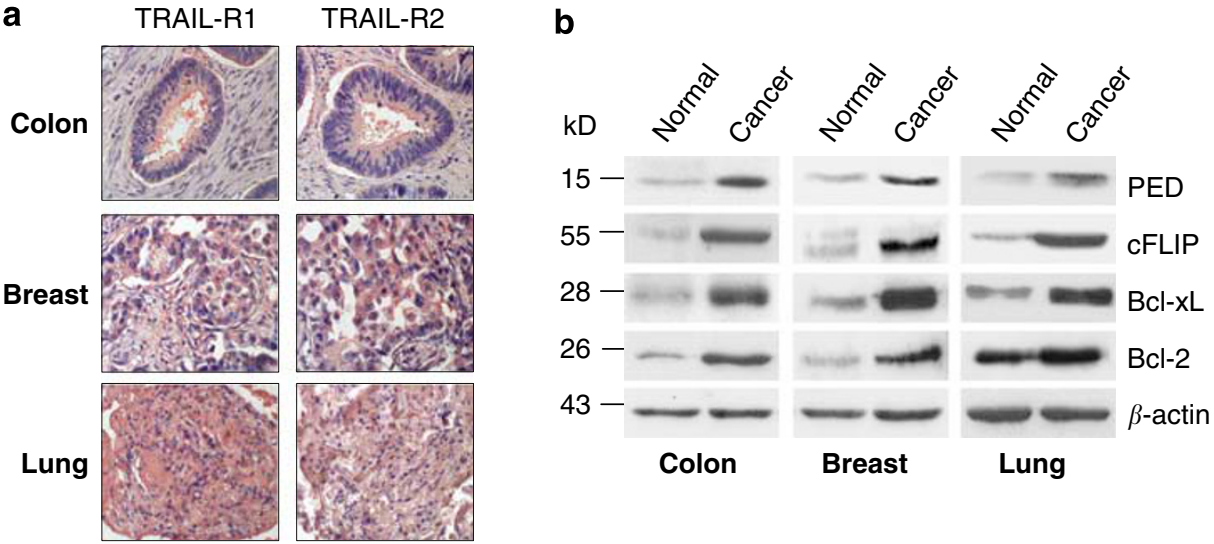

C

Colon

Breast

Lung
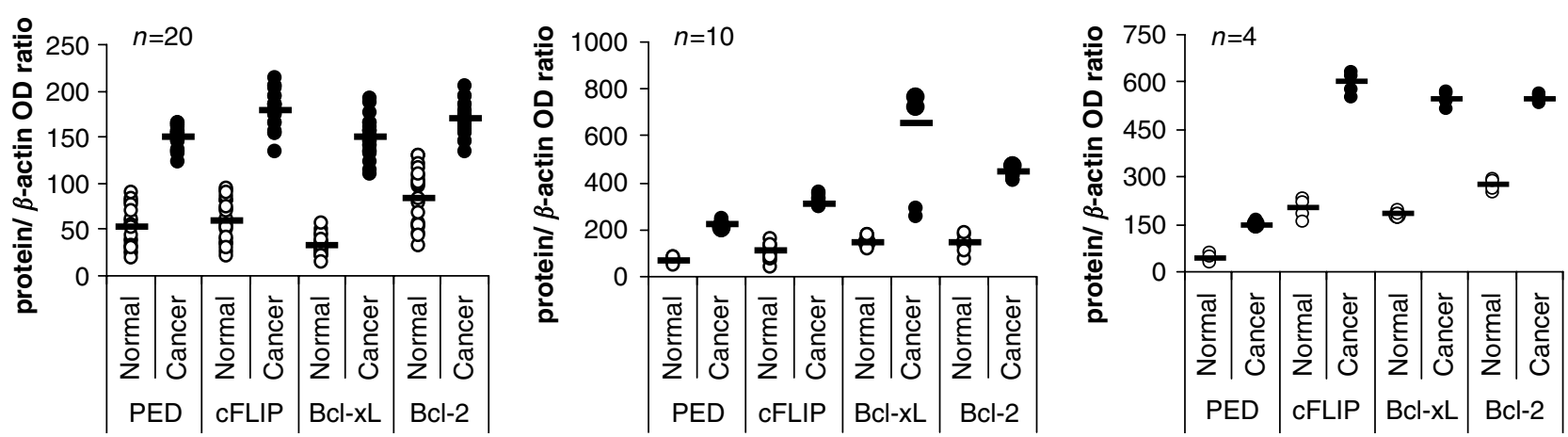

Figure 2 Expression of TRAIL receptors and various apoptotic proteins in epithelial cancer cells. (a) Immunohistochemical analysis of TRAIL-R1 and TRAIL-R2 on paraffin-embedded colon, breast and lung cancer sections revealed by 3-amino-9-ethylcarbazole (red staining). (b) Immunoblot analysis of PED, CFLIP, Bcl-xL and Bcl-2 in freshly purified primary colon, breast and lung normal or cancer cells. Loading control was assessed by detecting $\beta$-actin in the same membranes. (c) Relative band densities of antiapoptotic proteins as in (b). Data are representative of 20 independent experiments for colon, 1 of 10 for breast and 1 of 4 for lung

cFLIP levels were approximately three-fold higher in freshly purified cancer cells than in normal cells and that Bcl-xL was increased by about four-fold and $\mathrm{Bcl}-2$ by about two-fold (Figure $2 \mathrm{~b}$ and $\mathrm{c}$ ). Thus, the expression levels of various pro-survival proteins, together capable of blocking both arms of the apoptosis signaling pathway, were clearly increased in epithelial cancer cells. These results suggest that the observed resistance to chemotherapy and death receptor triggering could be due to the upregulation of antiapoptotic molecules.

Autocrine production of IL-4 increases growth and survival of epithelial cancer cells. We next investigated whether IL-4 and/or IL-10 and their respective receptors are also present in other types of epithelial neoplasia. Strikingly, immunohistochemical analysis revealed that the vast majority of solid tumors investigated highly expressed IL-4. In summary, tumor cells isolated from 73 of 85 colon (86\%), 27 of 32 breast (84\%) and 6 of 9 lung (67\%) cancers expressed IL-4 (Figure 3a). Moreover, IL-4R $\alpha$ was expressed in all normal and cancer tissues analyzed (Figure 3a). By contrast, we found that IL-10 was either not expressed at all or only at low levels in these tumors (data not shown). This result suggested that neoplastic cells themselves might produce IL-4 that could act in an autocrine/paracrine manner. However, to test whether T-cell infiltrates, possibly
IL-4 producing $\mathrm{T}_{\mathrm{H}} 2$ cells, which are often found in tumors, could be the source of this cytokine, we examined whether the reactivity observed in tumor tissues was due to the release of the cytokine by infiltrating $\mathrm{T}_{\mathrm{H}} 2$ cells or by the tumor cells themselves. We therefore analyzed freshly purified colon, breast and lung normal and cancer cells on the mRNA and protein levels by real-time PCR and enzyme-linked immunosorbent assay (ELISA), respectively. We controlled for the absence of contaminating infiltrating immune cells by flow cytometry analysis for CD45 (data not shown). In agreement with the results obtained by immunohistochemical analysis, purified cancer cells but not primary cells obtained from normal related tissue specimens expressed IL-4 at both mRNA (Figure $3 b$ ) and protein levels, the latter was detectable in colon, breast and lung cancer cells at the levels of $4.6 \pm 1.2,5 \pm 1.8$ and $3.8 \pm 1.8 \mathrm{pg} /$ $\mathrm{ml}$, respectively (Figure $3 \mathrm{c}$ ). This result demonstrates that the autocrine production of IL-4 apart from thyroid tumors applies also to other malignant epithelial tumors.

IL-4R $\alpha$ was also expressed in normal cells. Hence, tumorderived IL-4 may not only affect cancer cells but also the tumor microenvironment by influencing the growth behavior of surrounding normal cells. Thus, to investigate a possible role of IL-4 on normal cells, we cultured freshly purified epithelial cells from colon, breast or lung in the presence or absence of IL-4 and determined cell growth. We found that IL-4 
a

Colon

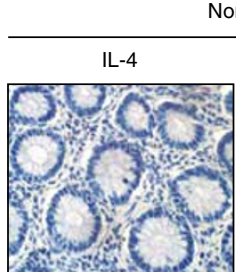

Normal

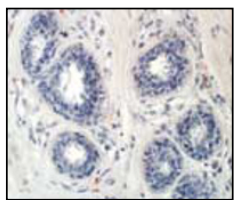

Lung

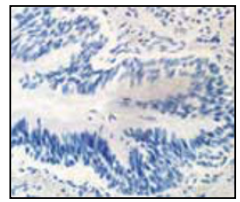

b
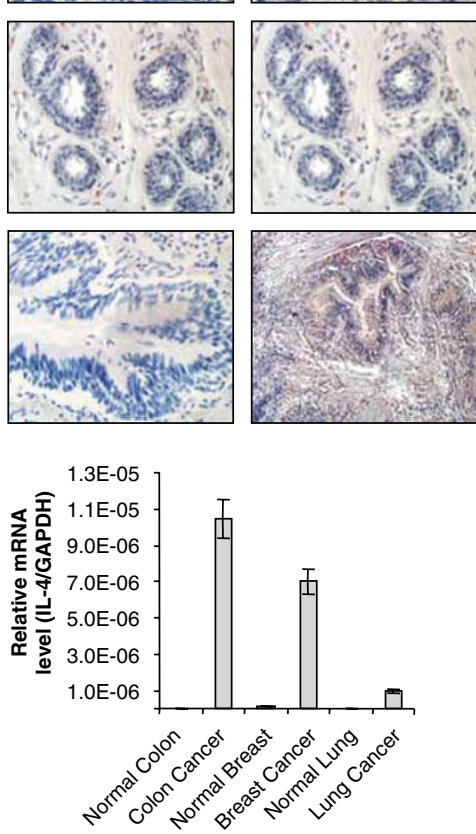

Cancer
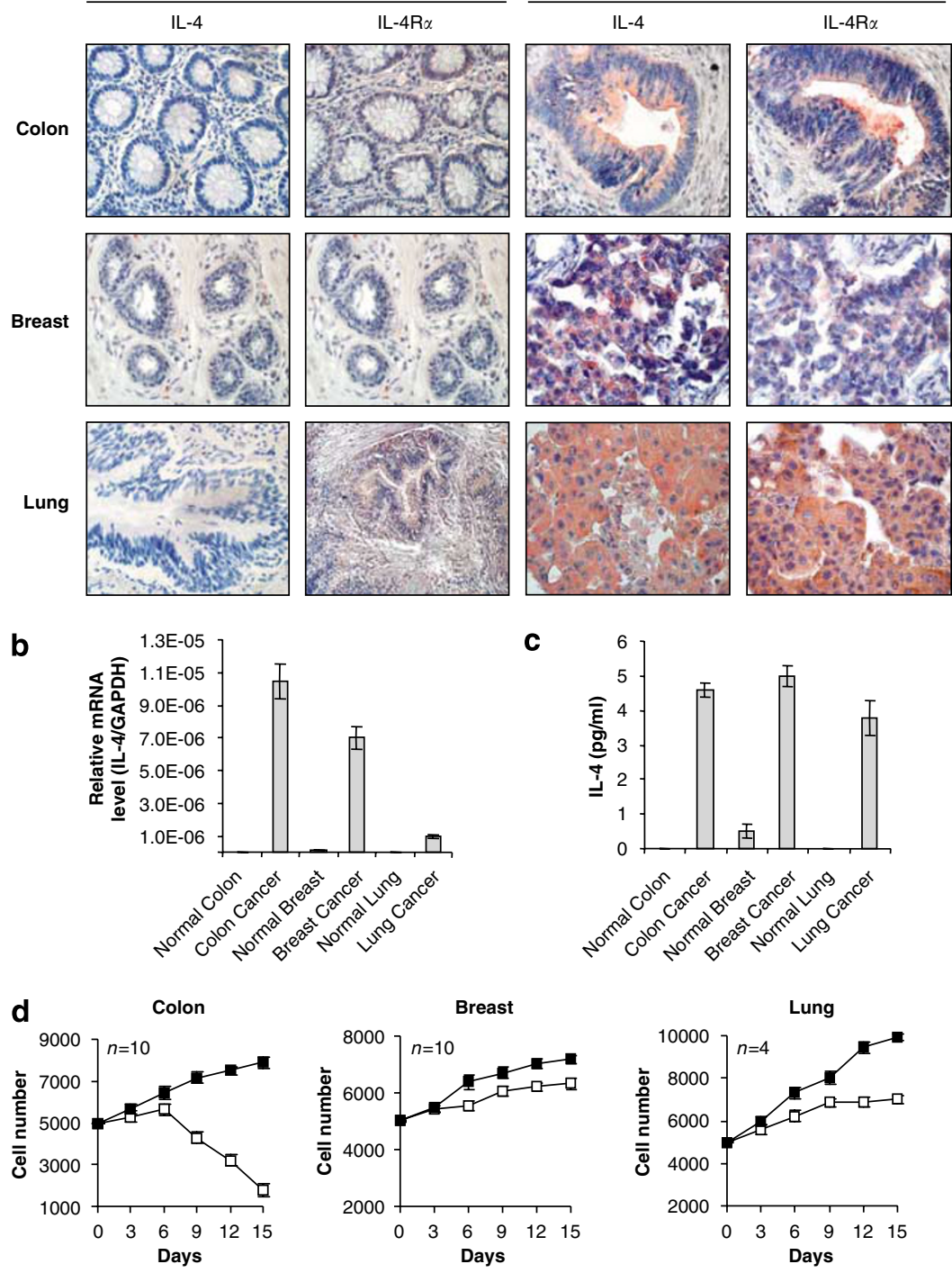

$\longrightarrow$ control $\longrightarrow$ IL-4
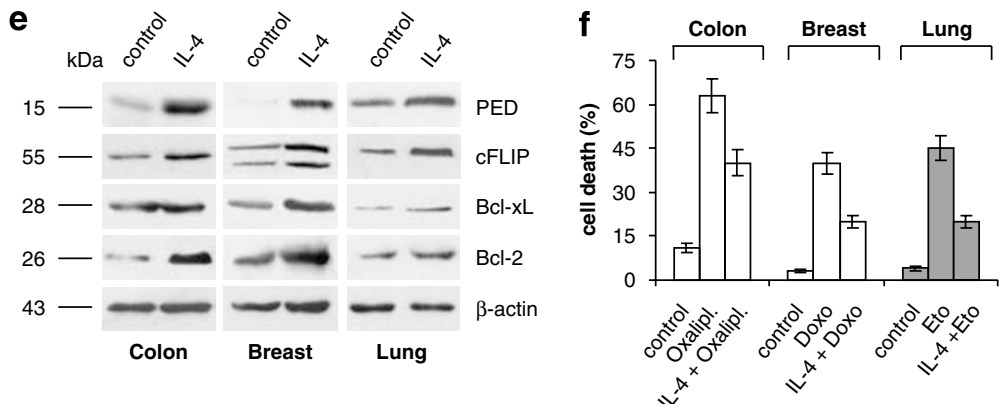

Figure 3 IL-4 is autocrinely produced by epithelial cancer cells and increases survival rate. (a) Immunohistochemical analysis of IL-4 and IL-4R $\alpha$ on paraffin-embedded sections from colon, breast and lung normal or cancer specimens (red staining). One representative of 73 of 85 colon, 27 of 32 breast and 6 of 9 lung cancer specimens is shown. (b) Real-time PCR analysis of IL-4 mRNA levels on freshly purified normal and cancer cells from colon, breast and lung tissues. (c) Quantification of IL-4 production in freshly purified normal and cancer cells as in (b) by an IL-4-specific ELISA. (d) Cell growth of colon, breast and lung primary normal cells up to 15 days following exposure to IL-4 (20 ng/ml) (filled squares) or PBS (open squares). (e) Western blot analysis of PED, cFLIP, Bcl-xL and Bcl-2 in purified colon, breast and lung normal cells following exposure to IL-4 for $48 \mathrm{~h}$. Loading control was performed by using $\beta$-actin in the same membranes. Data are representative of 10 independent experiments for colon and breast and 4 for lung, each using specimens or cells from different donors. (f) Cell death percentage of primary normal cells untreated or pretreated with IL-4 (20 ng/ml) for $72 \mathrm{~h}$ and subsequently exposed to oxaliplatin (oxalipl; $100 \mu \mathrm{M}$ ), doxorubicin (doxo; $5 \mu \mathrm{M}$ ) or etoposide (eto; $5 \mu \mathrm{M}$ ) for $24 \mathrm{~h}$. The results shown are the mean \pm S.D. of four independent experiments 
significantly increased the growth rate of primary cells isolated from all these tissues (Figure 3d). Moreover, exogenous IL-4 increased the protein levels of PED/PEA-15, cFLIP, Bcl-xL and $\mathrm{Bcl}-2$ in normal colon, breast and lung cells (Figure $3 e$ ) and rendered not only cancer cells but also surrounding nontransformed cells less sensitive to chemotherapy-induced apoptosis (Figure $3 f$ ).

IL-4 neutralization promotes growth arrest and cell death induced by TRAIL or chemotherapy in cancer cells. To test whether the autocrine production of IL-4 was responsible for resistance to chemotherapy- and death ligand-induced cell death and possibly also for accelerated growth of the epithelial cancer cells, we next investigated whether the blockade of IL-4 was capable of reversing this phenotype. We therefore exposed primary colon, breast and lung cancer cells to IL-4-neutralizing monoclonal antibody (anti-IL-4), either alone or in combination with chemotherapeutic drugs, which are usually applied in these types of cancer or TRAIL.

We found that IL-4 neutralization alone already significantly decreased the growth rate of primary colon, breast and lung tumor cells in vitro (Figure 4a). Furthermore, we determined the expression levels of the antiapoptotic proteins that were shown to be upregulated in IL-4-treated normal cells. Neutralization of IL-4 was sufficient to efficiently downregulate the expression levels of the antiapoptotic proteins PED/PEA15, cFLIP, Bcl-xL and Bcl-2 (Figure 4b). To study whether the production of IL-4 by tumor cells could be responsible for apoptosis resistance in epithelial cancer, we exposed freshly purified colon, breast and lung cancer cells to anti-IL-4 either alone or together with conventional chemotherapeutic agents or TRAIL. We found that in most cases pretreatment with anti-IL-4 strongly sensitized primary epithelial cancer cells to apoptosis induction by conventional chemotherapeutics. Primary colon and lung cancer cells were also sensitized to TRAIL-induced apoptosis, whereas in primary breast cancer cells TRAIL sensitization was only marginal (Figure $5 a-d$ ). Notably, some tumor samples retained co-resistance to both combinatorial treatments as observed in 4 of 20 colon, 2 of 10 breast and 1 of 4 lung specimens (Figure $5 \mathrm{~d}$ ).

\begin{abstract}
IL-4 blockade sensitizes cancer cells to chemotherapy or TRAIL in vivo. We next determined whether IL-4 may also act as an autocrine survival factor of cancer cells in vivo, and whether its neutralization may enhance the therapeutic benefit of systemic treatment with chemotherapy or TRAIL. Considering that adherent primary colon and breast cancer cells fail to engraft in immunodeficient mice (data not shown), we tested tumorigenic human colon T84 and breast BT549 cancer cell lines for the expression of IL-4 and IL-4R $\alpha$ to establish an in vivo model. T84 and BT549 cancer cells expressed both IL-4 and IL-4R $\alpha$ (Figure $6 a$ and b). IL-4 production as determined by ELISA was $12 \pm 1.2 \mathrm{pg} / \mathrm{ml}$ for T84 and $10 \pm 0.9 \mathrm{pg} / \mathrm{ml}$ for BT549 cancer cell lines (Figure 6b). In addition, IL-4-neutralization in T84 and BT549 resulted in a reduction of cellular growth rate up to 15 days and reduced the levels of the antiapoptotic proteins (Figure 6c and d). Moreover, in the absence of IL-4neutralization, T84 and BT549 cells were almost completely resistant to in vitro cell death induction by oxaliplatin and TRAIL, respectively. However, when cultured in the presence
\end{abstract}
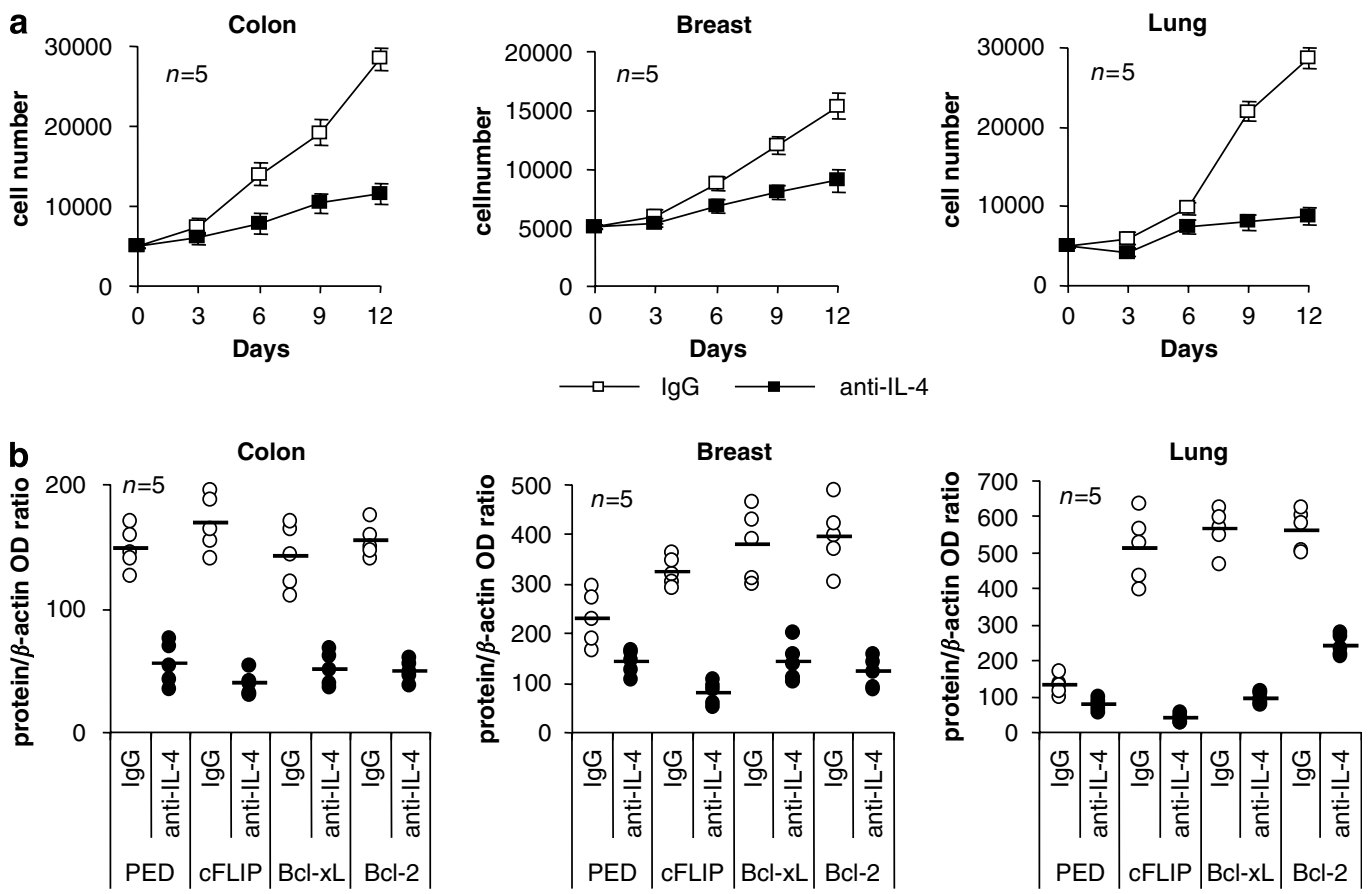

Figure 4 IL-4 neutralization promotes growth arrest in colon, breast and lung carcinoma cells in vitro. (a) Cell number of colon, breast and lung cancer cells treated with IgG (open squares) or anti-IL-4 (10 $\mu \mathrm{g} / \mathrm{ml}$ ) (filled squares) up to 12 days. (b) Relative band densities of PED, FLIP, Bcl-xL and Bcl-2 in cancer cells treated as in (a). Data are mean \pm S.D. of five independent experiments, each performed with cells from different donors 

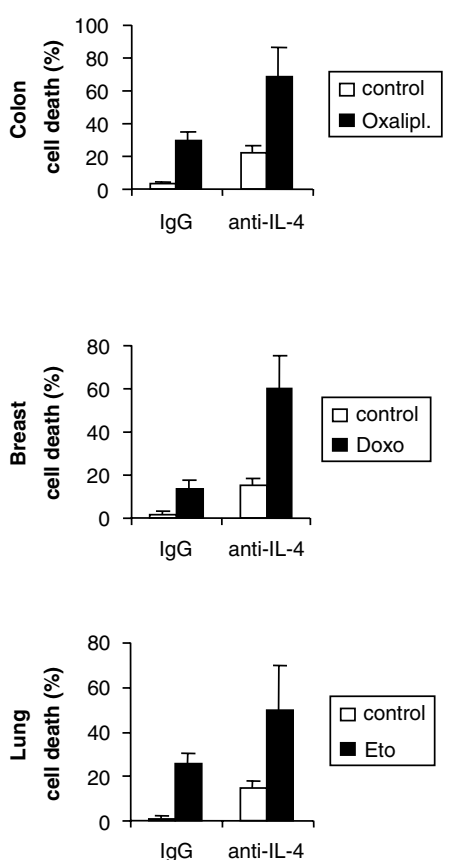

b
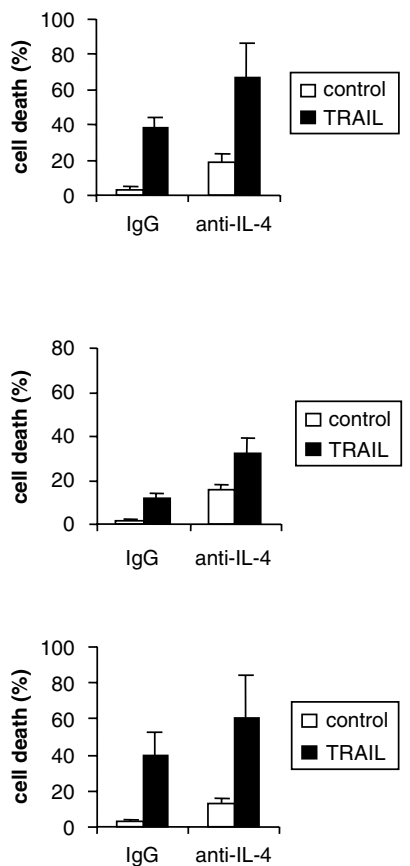
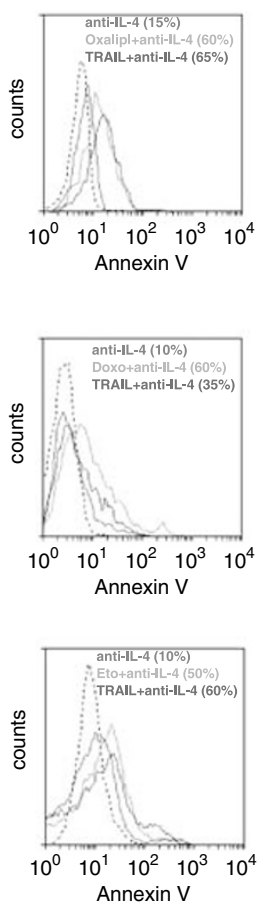

d
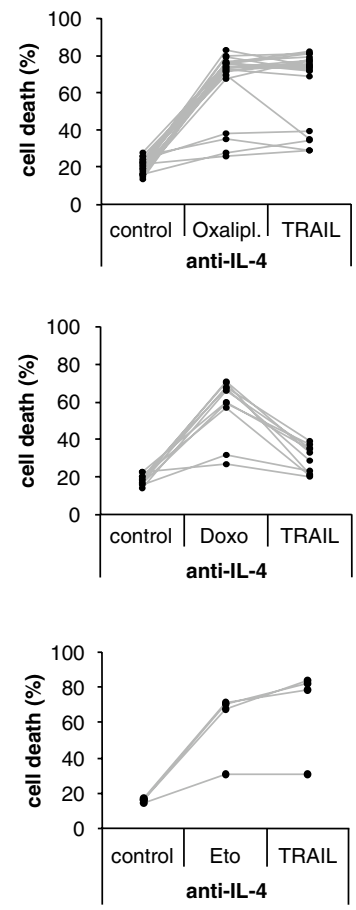

Figure 5 IL-4 neutralization sensitizes colon, breast and lung carcinoma cells to chemotherapy- and TRAIL-induced cell death. (a, b) Cell death percentage of purified colon, breast and lung tumor cells pretreated with lgG or anti-IL-4 (10 $\mu \mathrm{g} / \mathrm{ml})$ for $48 \mathrm{~h}$ and subsequently exposed to oxaliplatin (oxalipl; $100 \mu \mathrm{M})$, doxorubicin (doxo; $5 \mu \mathrm{M})$ or etoposide (eto; $5 \mu \mathrm{M}$ ), respectively, for additional $24 \mathrm{~h}$ (a) or TRAIL $(200 \mathrm{ng} / \mathrm{ml})(\mathbf{b})$, for additional $12 \mathrm{~h}$ (filled bars). PBS was used as control treatment (open bars). (c) Annexin $\checkmark$ representative profiles of colon, breast and lung cancer cells treated as in $(\mathbf{a}, \mathbf{b})$. (d) Cell death percentage of purified colon, breast and lung tumor cells treated as in $(\mathbf{a}, \mathbf{b})$. Each line represents data from an individual patient. Data are mean \pm S.D. of 20 independent experiments for colon, 10 for breast and 4 for lung

of anti-IL-4, both the cell lines were readily sensitized to apoptosis induction by these stimuli (Figure 6e). Yet, to serve as suitable models to test a possible therapeutic effect of inhibition of IL-4 in vivo, tumor cells would have to maintain the expression of both IL-4 and its receptor after xenotransplantation. We therefore tested whether this was the case and, indeed we found both proteins to be expressed in subcutaneously grown tumors derived from T84 colon and BT549 breast cancer cells (Figure 7a). Hence, we could next determine whether the neutralization of IL-4 may be of therapeutic benefit in vivo. We therefore treated mice carrying either human T84 colon or BT549 breast cancer xenografts with anti-IL-4 alone or in combination with oxaliplatin or TRAIL, respectively. When mice bearing T84 or BT549 tumors were treated with anti-IL-4 alone, tumor growth was only marginally diminished (Figure $7 \mathrm{~b}$ and $\mathrm{c}$ ). When mice were treated with oxaliplatin or TRAIL alone, tumor growth was slowed down in both cases. However, this effect was not very pronounced. Taken together, these data indicate that treatment with anti-IL-4, oxaliplatin or TRAIL alone is not sufficient to effectively prevent subcutaneous growth of T84 colon and BT549 breast cancer xenografts (Figure $7 \mathrm{~b}$ and $\mathrm{c}$ ). However, when anti-IL-4 was combined with oxaliplatin to treat T84-tumor-bearing mice or with TRAIL to treat BT549-tumor-bearing mice, tumor growth was drastically reduced (Figure $7 \mathrm{~b}$ and $\mathrm{c}$ ). In situ terminal deoxynucleotidyl transferase (TdT)-mediated dUTP nickend labeling (TUNEL) analysis of paraffin-embedded sections of T84- and BT459-derived tumor mass in mice treated with anti-IL-4, oxaliplatin or TRAIL alone or in combinations showed that apoptotic events were significantly increased in tumors obtained from mice treated with anti-IL-4 plus oxaliplatin or anti-IL-4 plus TRAIL, respectively (Figure $7 d$ and $e$ ). These data indicate that IL-4 neutralization significantly enhances the effectiveness of both chemotherapy and TRAIL treatment through apoptosis induction in tumor cells in vivo. Taken together, our findings suggest that the production of IL-4 may play a general role in cancer cell survival and that the interference with its effect in tumor cells may represent a novel strategy for the treatment of epithelial cancers.

\section{Discussion}

Apoptosis resistance of cancer cells can be achieved by overexpression of an oncogene or loss of expression of a tumor suppressor gene. ${ }^{18}$ Production of immunosuppressive cytokines constitutes an additional survival strategy used by tumor cells to evade the recognition of the immune system. Both infiltrating $\mathrm{T}$ cells in the tumor microenvironment and cancer cells can be the source of these molecules. ${ }^{12,19,20}$ It has been shown that $\mathrm{T}_{\mathrm{H}} 2$ cytokines downregulate antitumor immunity leading to cancer progression and metastasis formation. Accordingly, patients affected by a variety of human tumors express high levels of $\mathrm{T}_{\mathrm{H}} 2$ cytokines in the periphery and in the tumor microenvironment, which correlate 
b

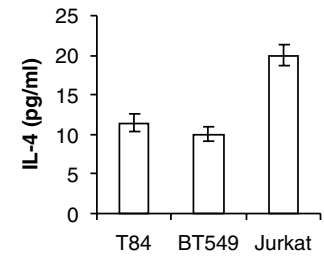

C

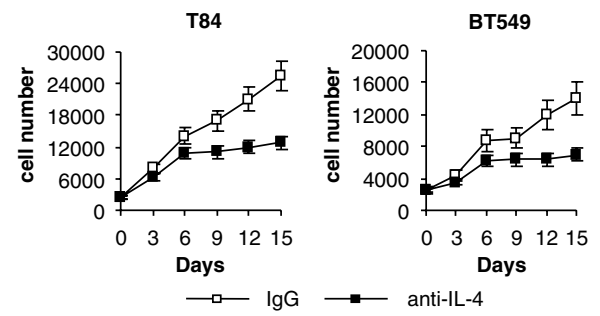

d

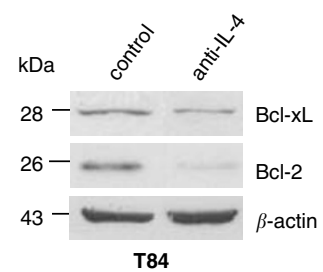

a

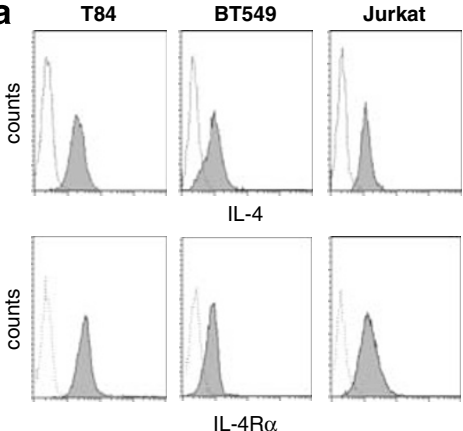

Figure 6 In vitro sensitization of colon T84 and breast cancer BT549 cell lines to chemotherapy- or TRAIL-induced cell death following anti-IL-4 treatment. (a) Flow cytometry analysis of IL-4 and IL-4R $\alpha$ on T84 and BT549 cells. PMA/ionomycin-treated Jurkat cells were used as a positive control. (b) Quantification of IL-4 production in T84 and BT549 cells by an IL-4-specific ELISA. (c) Cell number of T84 and BT549 cells after treatment with lgG (open squares) or anti-IL-4 (10 $\mu \mathrm{g} / \mathrm{ml}$ ) (filled squares) up to 15 days. (d) Immunoblot analysis of PED, CFLIP, Bcl-xL and Bcl-2 in T84 and BT549 cells treated as in (c). Loading controls were performed by using $\beta$-actin in the same membranes. (e) Percentage of cell death on T84 and BT549 cells treated with IgG or anti-lL-4 (10 $\mu \mathrm{g} / \mathrm{ml}$ ), either alone (open bars) or in combination with oxaliplatin (100 $\mu \mathrm{M}$ ) (gray bars) or TRAIL $(200 \mathrm{ng} / \mathrm{ml}$ ) (filled bars). Data are mean \pm S.D. of six independent experiments

with the stage and grade of malignancy. ${ }^{21,22}$ Particularly, IL-4 plays a major role in inducing $\mathrm{T}_{\mathrm{H}} 2$ responses acting through IL-4R $\alpha$ and activating the Janus kinase/signal transducer and activator of transcription (JAK/STAT) signaling cascade. ${ }^{17,23}$

Recently, IL-4 has been shown to induce apoptosis in hepatocarcinoma cells ${ }^{24}$ and a similar finding has been reported in renal cell carcinoma (RCC), where in vitro treatment of tumor cells with IL-4 and tumor necrosis factor- $\alpha$ is shown to increase RCC apoptosis. ${ }^{25}$ However, this point remains controversial since several clinical trials of IL-4 therapy for the treatment of both hematologic and nonhematologic cancers have been disappointing, with little antitumor effects or even with an increase in the number of malignant cells. ${ }^{26-28}$ Conversely, it has recently been demonstrated that IL-4 may suppress cancer-directed immunosurveillance, facilitating pancreatic tumor growth and metastasis. ${ }^{15}$ Similarly, IL-4 has been more recently demonstrated to inhibit cell apoptosis, which could help in promoting tumor growth, increasing the expression of antiapoptotic genes cFLIP and Bcl-xL and protecting cells from CD95- and chemotherapy-induced apoptosis of cancer cells from prostate, breast and bladder cancers, following IL-4 in vitro treatment. $^{29}$

Moreover, we have previously shown that refractoriness of thyroid cancer cells to chemotherapy and death receptors is due to the concomitant production of IL-4 and IL-10. ${ }^{16,17}$ In the present study, we provide evidence that other epithelial tumors, including tumors of the colon, breast and lung, produce IL-4 in an autocrine manner. This cytokine is likely to be associated with the high proliferation rate of tumor cells and with the inhibition of tumor cell apoptosis through upregulation of proteins that block the extrinsic as well as the intrinsic apoptotic pathway. Here, we demonstrate that inhibition of IL-4 reverses this resistance phenotype both in vitro and in vivo, suggesting that it may constitute a novel therapeutic strategy for the treatment of different types of epithelial neoplasia.

IL-4 is structurally related to IL-13, which competes for binding to its cell surface receptor exhibiting many similar biological effects. The molecular basis for this functional overlap has been attributed mainly to a shared use of the receptor complex for the IL-4 type II receptor, predominantly composed of the IL-4R $\alpha$ and IL-13R $\alpha 1 .{ }^{30}$ Alternatively, IL-13 may bind with even greater affinity to IL-13R $\alpha 2$, which fails to induce a signal, indicating that it acts as a decoy receptor. ${ }^{31}$

We thus investigated the expression of the IL-13 protein and its decoy IL-13R $\alpha 2$. We found that IL-13 was undetectable in normal and cancer epithelial cells from colon and in breast tissue, while IL-13R $\alpha 2$ was highly expressed in normal than in cancer colon cells and equally expressed in breast cells (data not shown). These data suggest that the protective effect observed in carcinoma cells is primarily due to the IL-4 autocrine production.

We and others have found that although the two apoptosisinducing TRAIL receptors are expressed in epithelial cancer cells, including those from colon, breast and lung, their triggering often does not lead to a significant induction of cell death. $^{32,33}$ In particular, here, we report that all the epithelial 


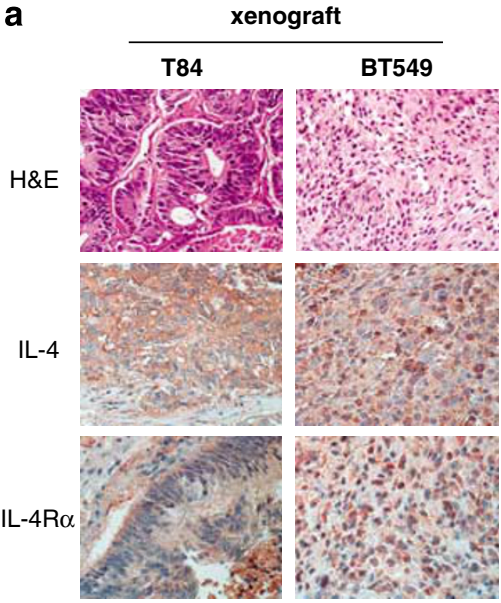

d

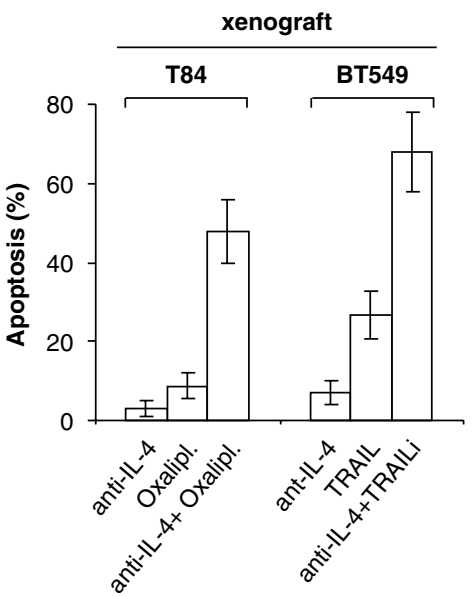

b

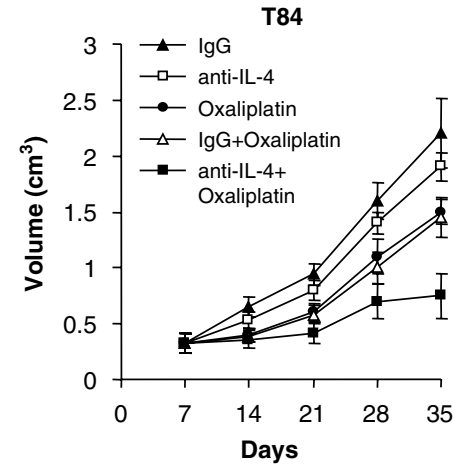

C

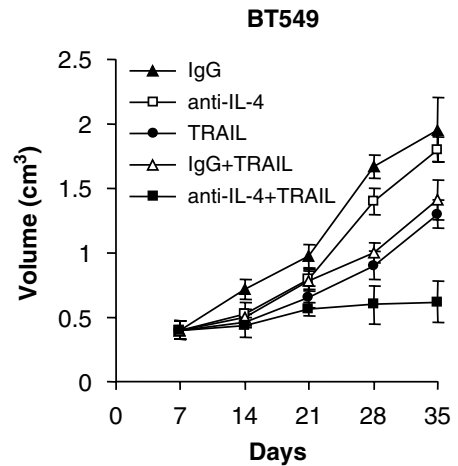

e

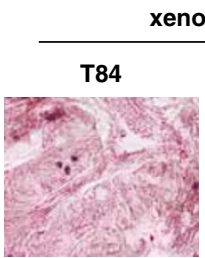

anti-IL-4

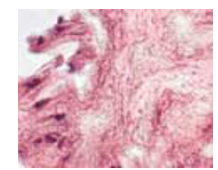

Oxaliplatin

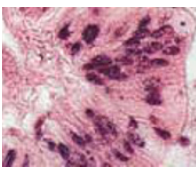

anti-IL-4+

Oxaliplatin nograft

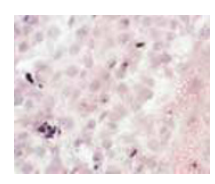

anti-IL-4

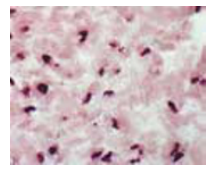

TRAIL

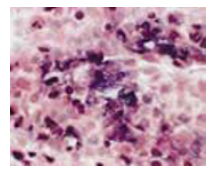

anti-IL-4+TRAIL

Figure 7 IL-4 neutralization sensitizes cancer cells to chemotherapy and to TRAIL-induced cell death in vivo. (a) H\&E and immunohistochemical analysis of IL-4 on paraffin-embedded sections of tumors generated in nude mice by T84 and BT549 cancer cells (red staining) $(\times 40$ magnification). Nuclei were counterstained by hematoxylin (blue color). One representative of four independent experiments is shown. (b, c) In vivo growth of subcutaneous colon and breast carcinoma tumor xenografts after treatment with $\mathrm{IgG}$ or anti-IL-4 $\left(10 \mu \mathrm{g} / \mathrm{cm}^{3}\right)$, alone or in combination with oxaliplatin $(0.40 \mathrm{mg} / \mathrm{kg})$ or TRAIL $(30 \mathrm{mg} / \mathrm{kg})$. Data are mean \pm S.D. of eight independent experiments. (d) Percentage of apoptotic events measured on sections of subcutaneous tumors (four per group) generated by T84 and BT549 and treated with anti-IL-4, oxaliplatin (oxalipl.) or TRAIL alone or with anti-IL-4 plus oxaliplatin or anti-IL-4 plus TRAIL and stained for TUNEL. Cells $\left(5 \times 10^{5}\right)$ per tumor were counted and the percentage of apoptotic event was calculated. Samples were analyzed six weeks after treatment had started. (e) A representative TUNEL staining on paraffin-embedded sections of tumor xenografts treated as in (c)

cancer cells examined are only partially sensitive to TRAIL and to chemotherapeutic drugs with a cell death rate ranging between 15 and $40 \%$. High expression of antiapoptotic molecules is commonly found in human cancers and contributes to both neoplastic cell expansion and resistance to the therapeutic action of cytotoxic drugs and death receptor triggering. ${ }^{34,35}$ Several studies have shown that functional blockade of antiapoptotic factors can either restore the apoptotic process in tumor cells or sensitize them to chemotherapy- and death ligand-induced apoptosis. ${ }^{36,37}$ Accordingly, we showed that cancer cells express high levels of the antiapoptotic proteins PED/PEA-15, cFLIP, Bcl-xL and $\mathrm{Bcl}-2$. This finding may explain why cancer cells despite expressing high levels of TRAIL-R1/R2 are refractory to apoptosis induction, even in the presence of high concentrations of a highly active recombinant form of TRAIL, and why at the same time they are resistant to the effects of conventional chemotherapeutic drugs.

IL-4 neutralization reduced the growth rate of cancer cells in vitro and rendered them more susceptible to chemotherapyand TRAIL-induced cell death, both in vitro and in vivo, indicating that this cytokine acts as a survival factor for epithelial cells.

Interestingly, in vivo treatment with anti-IL-4, chemotherapy or TRAIL alone was not sufficient to effectively prevent subcutaneous growth of colon and breast cancer cell line xenografts. However, when IL-4-neutralizing antibody was combined with chemotherapy or TRAIL, tumor growth was 
considerably decreased and apoptotic events were significantly increased. Thus, inhibition of IL-4-IL-4R interaction reprograms cancer cells, exemplified by the concomitant downregulation of at least four antiapoptotic factors, rendering them sensitive to apoptosis induction by chemotherapy and TRAIL. Anti-IL-4 therapeutics have been tested in clinical trials of respiratory diseases, such as asthma and allergies, and no adverse effects were observed. ${ }^{38}$ In addition, TRAIL has been used quite extensively in clinical trials even in combination with chemotherapeutics. The toxicity potential for the combinations of IL-4 antagonists with TRAIL and/or with chemotherapy is not yet known and needs to be carefully addressed in clinical trials. ${ }^{39}$

One of the main physiological functions of $\mathrm{IL}-4$ is to influence the immune system toward the production of $\mathrm{T}_{\mathrm{H}^{2}} 2$ cells and suppression of the production of IFN- $\gamma$-producing $\mathrm{T}_{\mathrm{H}} 1$ cells, the latter being important in efficient tumor immunity. ${ }^{40}$ Such skewing of the immune system toward a $T_{H} 2$ rather than a $T_{H} 1$ response is reminiscent of a situation often encountered in cancer patients. ${ }^{41}$ Our data suggest that this diversion of the immune system may be another subversive consequence of the tumor cells' production of IL-4, which would again favor tumor cell survival by preventing the formation of a $\mathrm{T}_{\mathrm{H}} 1$ environment that would be less favorable for them.

In conclusion, we provide evidence that IL-4 acts as a survival factor on epithelial cells by increasing the expression of antiapoptotic molecules rendering them resistant to the induction of apoptosis. We suggest that specific interference with signaling events triggered by IL-4R $\alpha$ crosslinking in combination with the currently used therapeutic approaches and/or with TRAIL receptor agonists may be used as a novel promising treatment option for patients affected by epithelial cancer.

\begin{abstract}
Materials and Methods
Human tissues. Human colon, breast and lung tissue fragments were obtained, in accordance with the ethical standards of the institutional committee responsible for human experimentation of the University of Palermo, from 85 patients affected by colon adenocarcinoma (age range 55-70 years), 32 patients affected by ductal and lobular breast cancer (age range 40-55 years) and 9 patients affected by non-small cell lung cancer (NSCLC; age range 35-55 years). Histological diagnosis was based on the morphological microscopic features of carcinoma cells determining the histological type and grade. Grossly, all the colon tumors, except one that had a polypoid appearance, were ulcerative. On pathological staging, the infiltration was confined to the subserosa with no lymph node involvement in four cases (pT3, N0, M0 and Dukes B). Four cases showed infiltration of subserosa with lymph node involvement (pT3, N1, M0 and Dukes C), while in twelve cases nodal invasion and metastatic involvement of the liver were observed (pT4, N1, M1 and Dukes D). Seven of ten breast carcinomas analyzed were invasive ductal and three out of ten were invasive lobular. All the four NSCLCs analyzed were adenocarcinomas. Normal epithelial cells were obtained from the peri-tumoral tissues of the surgically removed specimens.
\end{abstract}

Human primary cell purification and apoptosis induction. Tissues from colon, breast and lung were digested for $2 \mathrm{~h}$ with collagenase $(1.5 \mathrm{mg} / \mathrm{ml})$ (Gibco BRL, Grand Island, NY, USA) and hyaluronidase (20 $\mathrm{g} / \mathrm{ml})$ (Sigma Chemical Co., St. Louis, MO, USA) as previously described. ${ }^{35}$ Normal colon tissue specimens were extensively washed in DMEM and digested with collagenase $P$ $(0.4 \mathrm{U} / \mathrm{ml})$ and dispase I $(1.2 \mathrm{U} / \mathrm{ml})$ for $4 \mathrm{~min}$ at $37^{\circ} \mathrm{C}$. Crypt-like structures were obtained by mechanical dissociation. Epithelial cells were purified from the digested tissues by hematopoietic cell depletion with anti-CD45-coupled beads (Dynal; Wirral Merseyside, UK) followed by $12 \mathrm{~h}$ of flask adherence, which allowed removal of other cells. Fibroblasts were depleted exposing cell cultures to trypsin + EDTA for $1 \mathrm{~min}$.

Once digested, cells were maintained on plastic in DMEM medium (Euroclone Ltd., West York, UK) at $37^{\circ} \mathrm{C}$ in a humidified atmosphere of $5 \% \mathrm{CO}_{2}$. After an additional $12 \mathrm{~h}$, cells were allowed to grow in a monolayer. Cells were detached with trypsin in $5 \mathrm{mM}$ EDTA for functional protein expression and gene transcript level analyses. Colon cells were cultured on plastic flask pre-coated with collagen at $10 \mu \mathrm{g} / \mathrm{cm}^{2}$ (Calbiochem GmbH, Darmstadt, Germany). Oxaliplatin $(0-200 \mu \mathrm{M})$, doxorubicin $(0-20 \mu \mathrm{M})$ (Sigma Chemical Co.) and etoposide (0-20 $\mu \mathrm{M})$ (Biomol, Plymouth Meeting, PA, USA) were used to determine time-course $(6-48 \mathrm{~h})$ and dose-response curves in primary human epithelial cancer cells while iz-TRAIL $(0-20 \mu \mathrm{g} / \mathrm{ml})^{42}$ treatment for $12 \mathrm{~h}$ was used to determine a dose-response curve in the same cells. T98G TRAIL-sensitive cell line was used as a positive control of TRAIL treatment. Primary cells from normal tissues and from cancerous lesions were cultured up to 15 and 12 days, respectively, in the presence or absence of human recombinant IL-4 $(20 \mathrm{ng} / \mathrm{ml}$ ) (Euroclone, Paignton, UK) or $10 \mu \mathrm{g} / \mathrm{ml}$ neutralizing $A b$ against human IL-4 (3007.11 mouse $\operatorname{lgG}_{1}$; R\&D Systems Europe $L t d)$. The pretreatment of primary cancer cells with anti-IL-4 Ab was also used to test the sensitization to the chemotherapeutic drugs of primary cancer cells.

The T84 human colon carcinoma cell line and the BT549 human ductal breast carcinoma cell line were cultured in DMEM/F12 with $10 \%$ FCS and RPMI 1640 with $5 \% \mathrm{FCS}$, respectively, in the presence or absence of anti-IL-4 Ab in combination with oxaliplatin $(100 \mu \mathrm{M})$ and TRAIL $(200 \mathrm{ng} / \mathrm{ml})$, respectively.

Survival and death assays. To evaluate apoptotic events, annexin V/ propidium iodide staining was performed and analyzed by flow cytometry. Alternatively, human purified cancer cells were plated in 96 -well plates in triplicate at 15000 cells per well and cultured for the indicated periods of time. The number of viable cells was detected by CellTiter Aqueous Assay Kit (Promega Corporation, WI, USA) following the manufacturer's instructions. HuT78 cells plated at $2 \times 10^{5} / \mathrm{ml}$ and treated with an agonistic anti-CD95 Ab $(\mathrm{CH}-11 ; 200 \mathrm{ng} / \mathrm{ml})$ were used as a positive control for cell death measurement.

Immunohistochemical analysis. Immunohistochemistry was performed on 6- $\mu \mathrm{m}$-thick paraffin-embedded sections of human colon, breast and lung normal or tumor samples or of subcutaneous tumors generated in nude mice by injection of T84 or BT549 tumor cells. Dewaxed sections were treated for $10 \mathrm{~min}$ in a microwave oven in $0.1 \mathrm{M}$ citrate buffer. Then, sections were incubated for $10 \mathrm{~min}$ with Trisbuffered saline (TBS) containing 10\% AB human serum to block unspecific binding. After elimination of excess serum, sections were exposed overnight at $4^{\circ} \mathrm{C}$ to specific Abs against TRAIL-R1 (TR1.02 mouse IgG1), TRAIL-R2 (TR2.21 mouse IgG1), IL-4 (B-S4 mouse Ig $\mathrm{G}_{1}$; Caltag Laboratories, Burlingame, CA, USA), IL-4R $\alpha$ (C-20 rabbit IgG; Santa Cruz Biotechnology Inc., Santa Cruz, CA, USA) or isotypematched controls at appropriate dilutions. Following exposure to primary Abs, sections were treated with biotinylated anti-rabbit or anti-mouse immunoglobulins, washed in TBS and then incubated with streptavidin peroxidase (LSAB 2 Kit; Dako Corporation, Carpinteria, CA, USA). Staining was detected using 3-amino-9ethylcarbazole as a colorimetric substrate. Counterstaining of cells was performed using aqueous hematoxylin.

Protein isolation and western blotting analysis. Cell pellets were resuspended in ice-cold NP-40 lysis buffer $(50 \mathrm{mM}$ Tris- $\mathrm{HCl}, \mathrm{pH} 7.5,150 \mathrm{mM} \mathrm{NaCl}$, $1 \mathrm{mM}$ EGTA, 1\% NP-40) containing protease and phosphatase inhibitors as previously described. ${ }^{13}$ Immunoblotting of Abs specific for PED/PEA-15 (rabbit $\operatorname{IgG}$ ), cFLIP (NF6 mouse IgG1; Alexis Biochemicals, Switzerland), Bcl-xL (H-5, mouse IgG ${ }_{1}$; Santa Cruz Biotechnology Inc.), Bcl-2 (124, mouse lgG ${ }_{1}$; Upstate Biotechnology Inc.) and actin (Ab-1, mouse IgM; Calbiochem $\mathrm{GmbH}$ ) was detected by HRP-conjugated anti-mouse or anti-rabbit Abs (Amersham Biosciences UK Limited, England) and visualized by a chemiluminescence detection system (SuperSignal West Dura Extended Duration Substrate; Pierce, IL, USA).

Real-time PCR analysis. Total RNA was prepared from cultured cells using the RNeasy Mini Kit (Qiagen GmbH, Germany) according to the manufacturer's instruction. Reverse transcription of total RNA was performed using the Highcapacity cDNA Archive Kit (Applied Biosystems, Foster City, CA, USA). Quantitative TaqMan PCR analysis was carried out with the ABI PRISM 7900HT Sequence Detection System (Applied Biosystems) in a reaction volume of $25 \mu \mathrm{l}$ containing $1 \times$ TaqMan Universal Master Mix (Applied Biosystems, Branchburg, NJ, USA) and $1 \times$ probes and primer sets Hs00174122_m1 (IL-4) (Taqman Gene Expression 
Assays; Applied Biosystems, Foster City) or $1 \times$ Hu GAPDH (Pre-Developed TaqMan Assay Reagents; Applied Biosystems, Warrington, UK). Reactions were performed using the following thermal cycler parameters: incubation at $50^{\circ} \mathrm{C}$ for $2 \mathrm{~min}$ and denaturation at $95^{\circ} \mathrm{C}$ for $10 \mathrm{~min}$, then 45 cycles of the amplification step (denaturation at $95^{\circ} \mathrm{C}$ for $15 \mathrm{~s}$ and annealing/extension at $60^{\circ} \mathrm{C}$ for $1 \mathrm{~min}$ ).

All amplification reactions were performed in triplicate and the relative quantification of IL-4 gene expression was expressed after normalization with the endogenous control, GAPDH. Data processing and statistical analysis were performed using the ABI PRISM SDS, software version 2.1 (Applied Biosystems, Foster City).

ELISA. IL-4 levels in primary cancer cells and T84 and BT549 cell lines were measured by quantitative sandwich ELISA, using a commercially available ELISA kit (Human Interleukin 4 ELISA; Euroclone). The minimum detectable dose of IL-4 was $0.5 \mathrm{pg} / \mathrm{ml}$. Streptavidin peroxidase was added after biotinylated anti-IL- 4 . The chromogen used was tetramethyl benzidine and the reaction was stopped by using $\mathrm{H}_{2} \mathrm{SO}_{4}$. Optical density readings were performed at $450 \mathrm{~nm}$ and corrected at $540 \mathrm{~nm}$ using GDV programmable MPT reader DV990BV6.

Flow cytometry analysis. For FACS analysis of IL-4 and IL-4R $\alpha$ expression on T84 and BT549 cells, R-PE-conjugated anti-human IL-4 rat monoclonal Ab (Caltag Laboratories) and R-PE-conjugated anti-human IL-4R $\alpha$ Ab (hIL4R-M57 mouse IgG1; BD Pharmingen, CA, USA) were used. Jurkat cells, exposed for $4 \mathrm{~h}$ to PMA $(10 \mathrm{ng} / \mathrm{ml})$ and ionomycin $(1 \mu \mathrm{M})$, were used as a positive control.

Animals and tumor system. Nude mice were purchased from Charles River Laboratories (Milan, Italy), housed 3-4 per cage and acclimatized to the animal housing facility for a minimum period of 1 week before beginning the experiments. All the experiments were carried out according to current regulations, observing the interdisciplinary principles and guidelines for the use of animals in research, marketing and education. Mice received subcutaneous injection of $2 \times 10^{6} \mathrm{~T} 84$ human colon cancer cells or $2 \times 10^{6}$ BT549 human ductal breast cancer cells in $200 \mu$ l of PBS and after 7 days, when well-established tumors of about $0.3 \mathrm{~cm}^{3}$ were detected, 10 mice per group were treated i.p. with oxaliplatin alone $(0.40 \mathrm{mg} / \mathrm{kg}$ on day 1 every week for 4 weeks) or with TRAIL alone (30 mg/kg once per day for five consecutive days followed by a once weekly dose until they were killed) or in combination with anti-IL-4 (R\&D Systems Europe Ltd; $10 \mu \mathrm{g} / \mathrm{cm}^{3}$ on day 1 and day 4 for 3 weeks) inoculated into the tumor. Controls were assessed using lgG isotypematched control or PBS. Tumors were measured weekly with a calliper and volumes were calculated on the basis of the formula: $(\pi / 6) \times$ larger diameter $\times$ (smaller diameter) $)^{2}$

TUNEL staining. TUNEL reaction was performed on paraffin-embedded sections of subcutaneous tumors generated by T84 or BT549 cell lines $(10 \mu \mathrm{m})$. Sections were post-fixed with paraformaldehyde for $20 \mathrm{~min}$ and permeabilized with $0.1 \%$ Triton $\mathrm{X}-100$ in $0.1 \%$ sodium citrate for $2 \mathrm{~min}$ on ice. Apoptosis was determined by In Situ Cell Death Detection AP Kit (Boehringer Mannheim, Indianapolis, IN, USA). DNA strand breaks were detected by 5-bromo-4-chloro-3indolyl-phosphate (Dako Corporation) substrate. Positive control was performed by pretreating specimens with DNAse I $(1 \mu \mathrm{g} / \mathrm{ml})$ to introduce nonspecific strand breaks, while the negative control was subjected to the same staining for TUNEL without TdT.

Statistical analysis. Percentage of apoptotic events was calculated from the values of the MTS assay and annexin V/propidium iodide staining. Data were expressed as mean \pm S.D. S.D. was calculated by the square root of the arithmetic mean of the squares of the deviations from the arithmetic mean. Intensity of band signals in exposed film was determined by densitometric scanning and analyzed using NIH IMAGE software version 1.62 (by Wayne Rasband, National Institutes of Health, Research Services Branch, NIMH). FLIP analysis was carried out by summing up the densities of the bands at 55 and $43 \mathrm{kDa}$ (for FLIPs, when detected) and then dividing by the density of the $\beta$-actin band. Results were expressed as protein/ $\beta$-actin OD ratio (OD).

Acknowledgements. This study was supported by grants from AIRC to $G$ Stassi and M Todaro and Programmi di Ricerca Scientifica di Rilevante Interesse Nazionale (PRIN) 2005 - prot. 2005052122002 to G Stassi. Y Lombardo is a recipient of an AIRC fellowship. $\mathrm{H}$ Walczak was supported by a grant of the
Deutsche Krebshilfe. MG Francipane and $A B$ Di Stefano are PhD students in Immunopharmacology at University of Palermo. We thank the Apogenix $\mathrm{GmbH}$, Heidelberg for support and criticism.

1. Reed JC. Dysregulation of apoptosis in cancer. J Clin Oncol 1999; 17: 2941-2953.

2. Hengartner MO. The biochemistry of apoptosis. Nature 2000; 407: 770-776.

3. Irisarri M, Plumas J, Bonnefoix T, Jacob MC, Roucard C, Pasquier MA et al. Resistance to CD95-mediated apoptosis through constitutive C-FLIP expression in a non-Hodgkin's lymphoma B cell line. Leukemia 2000; 14: 2149-2158.

4. Ahmad M, Shi Y. TRAIL-induced apoptosis of thyroid cancer cells: potential for therapeutic intervention. Oncogene 2000; 19: 3363-3371.

5. Walczak H, Sprick MR. Biochemistry and function of the DISC. Trends Biochem Sci 2001; 26: $452-453$

6. Ricci-Vitiani L, Pedini F, Mollinari C, Condorelli G, Bonci D, Bez A et al. Absence of caspase 8 and high expression of PED protect primitive neural cells from cell death. J Exp Med 2004; 200: 1257-1266.

7. Siegmund D, Mauri D, Peters N, Juo P, Thome M, Reichwein M et al. Fas-associated death domain protein (FADD) and caspase-8 mediate up-regulation of c-Fos by Fas ligand and tumor necrosis factor-related apoptosis-inducing ligand (TRAIL) via a FLICE inhibitory protein (FLIP)-regulated pathway. J Biol Chem 2001; 276: 32585-32590.

8. Sprick MR, Rieser E, Stahl H, Grosse-Wilde A, Weigand MA, Walczak H. Caspase-10 is recruited to and activated at the native TRAIL and CD95 death-inducing signalling complexes in a FADD-dependent manner but cannot functionally substitute caspase-8. EMBO J 2002; 21: 4520-4530.

9. Green DR, Reed JC. Mitochondria and apoptosis. Science 1998; 281: 1309-1312.

10. Kihara C, Tsunoda T, Tanaka T, Yamana H, Furukawa $Y$, Ono K et al. Prediction of sensitivity of esophageal tumors to adjuvant chemotherapy by cDNA microarray analysis of gene-expression profiles. Cancer Res 2001; 61: 6474-6479.

11. Watanabe T, Komuro Y, Kiyomatsu T, Kanazawa T, Kazama Y, Tanaka J et al. Prediction of sensitivity of rectal cancer cells in response to preoperative radiotherapy by DNA microarray analysis of gene expression profiles. Cancer Res 2006; 66: 3370-3374.

12. Yeh HH, Lai WW, Chen HH, Liu HS, Su WC. Autocrine IL-6-induced Stat3 activation contributes to the pathogenesis of lung adenocarcinoma and malignant pleural effusion. Oncogene 2006; 25: 4300-4309.

13. Stassi G, Di Liberto D, Todaro M, Zeuner A, Ricci-Vitiani L, Stoppacciaro A et al. Control of target cell survival in thyroid autoimmunity by $T$ helper cytokines via regulation of apoptotic proteins. Nat Immunol 2000; 1: 483-488.

14. Seder RA, Boulay JL, Finkelman F, Barbier S, Ben-Sasson SZ, Le Gros G et al. CD8+ T cells can be primed in vitro to produce IL-4. J Immunol 1992; 148: 1652-1656.

15. Prokopchuk O, Liu Y, Henne-Bruns D, Kornmann M. Interleukin-4 enhances proliferation of human pancreatic cancer cells: evidence for autocrine and paracrine actions. $\mathrm{Br} \mathrm{J}$ Cancer 2005; 92: 921-928.

16. Stassi G, Arena A, Speranza A, lannello D, Miceli M, Mastroeni P. Treatment of PBMC with killed Helicobacter pylori subverts the environment of inflammatory cytokines. New Microbiol 2003; 26: 227-231

17. Todaro M, Zerilli M, Ricci-Vitiani L, Bini M, Perez Alea M, Maria Florena A et al. Autocrine production of interleukin-4 and interleukin-10 is required for survival and growth of thyroid cancer cells. Cancer Res 2006; 66: 1491-1499.

18. Dai Y, Grant S. Targeting multiple arms of the apoptotic regulatory machinery. Cancer Res 2007; 67: 2908-2911.

19. Leu CM, Wong FH, Chang C, Huang SF, Hu CP. Interleukin-6 acts as an antiapoptotic factor in human esophageal carcinoma cells through the activation of both STAT3 and mitogen-activated protein kinase pathways. Oncogene 2003; 22: 7809-7818.

20. Seo N, Hayakawa S, Takigawa M, Tokura Y. Interleukin-10 expressed at early tumour sites induces subsequent generation of $\mathrm{CD} 4(+)$ T-regulatory cells and systemic collapse of antitumour immunity. Immunology 2001; 103: 449-457.

21. Wise GJ, Marella VK, Talluri G, Shirazian D. Cytokine variations in patients with hormone treated prostate cancer. J Urol 2000; 164 (3 Pt 1): 722-725.

22. Elsasser-Beile U, Kolble N, Grussenmeyer T, Schultze-Seemann W, Wetterauer U, Gallati $\mathrm{H}$ et al. Th1 and Th2 cytokine response patterns in leukocyte cultures of patients with urinary bladder, renal cell and prostate carcinomas. Tumour Biol 1998; 19: 470-476.

23. Chen XH, Patel BK, Wang LM, Frankel M, Ellmore N, Flavell RA et al. Jak1 expression is required for mediating interleukin-4-induced tyrosine phosphorylation of insulin receptor substrate and Stat6 signaling molecules. J Biol Chem 1997; 272: 6556-6560.

24. Aoudjehane L, Podevin P, Scatton O, Jaffray P, Dusanter-Fourt I, Feldmann G et al. Interleukin-4 induces human hepatocyte apoptosis through a Fas-independent pathway. FASEB J 2007; 21: 1433-1444.

25. Falkensammer $\mathrm{C}$, Johrer K, Gander H, Ramoner R, Putz T, Rahm A et al. IL-4 inhibits the TNF-alpha induced proliferation of renal cell carcinoma (RCC) and cooperates with TNFalpha to induce apoptotic and cytokine responses by RCC: implications for antitumor immune responses. Cancer Immunol Immunother 2006; 55: 1228-1237.

26. Whitehead RP, Lew D, Flanigan RC, Weiss GR, Roy V, Glode ML et al. Phase II trial of recombinant human interleukin-4 in patients with advanced renal cell carcinoma: a Southwest Oncology Group Study. J Immunother 2002; 25: 352-358. 
27. Margolin K, Aronson FR, Sznol M, Atkins MB, Gucalp R, Fisher RI et al. Phase Il studies of recombinant human interleukin-4 in advanced renal cancer and malignant melanoma. $J$ Immunother Emphasis Tumor Immunol 1994; 15: 147-153.

28. Lundin J, Kimby E, Bergmann L, Karakas T, Mellstedt H, Osterborg A. Interleukin 4 therapy for patients with chronic lymphocytic leukaemia: a phase I/II study. Br J Haematol 2001 112: $155-160$.

29. Conticello C, Pedini F, Zeuner A, Patti M, Zerilli M, Stassi G et al. IL-4 protects tumor cells from anti-CD95 and chemotherapeutic agents via up-regulation of antiapoptotic proteins. J Immunol 2004; 172: 5467-5477.

30. Mentink-Kane MM, Wynn TA. Opposing roles for IL-13 and IL-13 receptor alpha 2 in health and disease. Immunol Rev 2004; 202: 191-202.

31. Rahaman SO, Sharma P, Harbor PC, Aman MJ, Vogelbaum MA, Haque SJ. IL-13R(alpha)2, a decoy receptor for IL-13 acts as an inhibitor of IL-4-dependent signal transduction in glioblastoma cells. Cancer Res 2002; 62: 1103-1109.

32. Lippa MS, Strockbine LD, Le TT, Branstetter DG, Strathdee CA, Holland PM. Expression of anti-apoptotic factors modulates Apo2L/TRAIL resistance in colon carcinoma cells. Apoptosis 2007; 12: 1465-1478.

33. Sanlioglu AD, Dirice E, Aydin C, Erin N, Koksoy S, Sanlioglu S. Surface TRAIL decoy receptor-4 expression is correlated with TRAIL resistance in MCF7 breast cancer cells. BMC Cancer 2005; 5: 54

34. Espana L, Martin B, Aragues R, Chiva C, Oliva B, Andreu D et al. Bcl-x(L)-mediated changes in metabolic pathways of breast cancer cells: from survival in the blood stream to organ-specific metastasis. Am J Pathol 2005; 167: 1125-1137.
35. Stassi G, Todaro M, Zerilli M, Ricci-Vitiani L, Di Liberto D, Patti M et al. Thyroid cancer resistance to chemotherapeutic drugs via autocrine production of interleukin-4 and interleukin-10. Cancer Res 2003; 63: 6784-6790.

36. Mathas S, Lietz A, Anagnostopoulos I, Hummel F, Wiesner B, Janz M et al. c-FLIP mediates resistance of Hodgkin/Reed-Sternberg cells to death receptor-induced apoptosis. J Exp Med 2004; 199: 1041-1052.

37. Oltersdorf T, Elmore SW, Shoemaker AR, Armstrong RC, Augeri DJ, Belli BA et al. An inhibitor of Bcl-2 family proteins induces regression of solid tumours. Nature 2005; 435 677-681.

38. Borish LC, Nelson HS, Lanz MJ, Claussen L, Whitmore JB, Agosti JM et al. Interleukin-4 receptor in moderate atopic asthma. A phase I/II randomized, placebo-controlled trial. Am J Respir Crit Care Med 1999; 160: 1816-1823.

39. Huang Y, Sheikh MS. TRAIL death receptors and cancer therapeutics. Toxicol App Pharmacol 2007; 224: 284-289.

40. O'Garra A, Steinman L, Gijbels K. CD4+ T-cell subsets in autoimmunity. Curr Opin Immunol 1997; 9: 872-883.

41. Sun CF, Hsieh YY, Ngan KW, Wang WT. Search for immunomodulatory effects of blood transfusion in gastric cancer patients: flow cytometry of Th1/Th2 cells in peripheral blood. Ann Clin Lab Sci 2001; 31: 171-178.

42. Ganten TM, Koschny R, Sykora J, Schulze-Bergkamen H, Buchler P, Haas TL et al. Preclinical differentiation between apparently safe and potentially hepatotoxic applications of TRAIL either alone or in combination with chemotherapeutic drugs. Clin Cancer Res 2006; 12: 2640-2646. 